University of Nebraska - Lincoln

DigitalCommons@University of Nebraska - Lincoln

Faculty Publications, Department of Child, Youth, and Family Studies

Child, Youth, and Family Studies, Department of

2009

\title{
Effects of Marital Quality on Children in Brazilian Families
}

Stephen V. Stutzman

Brigham Young University - Utah

Richard B. Miller

Brigham Young University - Utah

Cody S. Hollist

University of Nebraska Lincoln, chollist2@unl.edu

Olga G. Falceto

Federal University of Rio Grande Do Sul, Brazil

Follow this and additional works at: https://digitalcommons.unl.edu/famconfacpub

Stutzman, Stephen V.; Miller, Richard B.; Hollist, Cody S.; and Falceto, Olga G., "Effects of Marital Quality on Children in Brazilian Families" (2009). Faculty Publications, Department of Child, Youth, and Family Studies. 84.

https://digitalcommons.unl.edu/famconfacpub/84

This Article is brought to you for free and open access by the Child, Youth, and Family Studies, Department of at DigitalCommons@University of Nebraska - Lincoln. It has been accepted for inclusion in Faculty Publications, Department of Child, Youth, and Family Studies by an authorized administrator of DigitalCommons@University of Nebraska - Lincoln. 


\title{
Effects of Marital Quality on Children in Brazilian Families
}

\author{
Stephen V. Stutzman* \\ Richard B. Miller* \\ Cody S. Hollist ${ }^{* *}$ \\ Olga G. Falceto***
}

\section{INTRODUCTION}

There is an extensive literature that has linked parental conflict to developmental difficulties in children. Included in the literature are five meta-analytic reviews (Buehler, Krishnakumar, Gaye, Anthony, Pemberton, Gerard, \& Barber, 1997; Depner, Leino, \& Chun, 1992; Erel \& Burman, 1995; Krishnakumar \& Buehler, 2000; Reid \& Crisafulli, 1990) which document the increased adjustment difficulties that children experience due to their parent's marital conflict and dissatisfaction. For example, the meta-analysis of 68 studies by Buehler et al., (1997) yielded an average effect size of .32 , which is considered moderate. Another meta-analysis (Depner et al., 1992) reviewed studies identifying the relationship between marital conflict and behavioral, psychological, and social functioning outcomes. Their study yielded effect sizes of $.46, .29$, and .33 for the respective outcomes. In addition, narrative reviews have documented the relationship between marital conflict and child outcomes (Bradford, Barber, Olsen, Maughan, Erickson, Ward, Stolz, 2004; Cummings \& Davies, 1994; Fincham \& Osborne, 1993; Grych \& Fincham, 2001; Katz \& Gottman, 1993; Kolko, Blakely, and Engleman, 1996; Zimet \& Jacob, 2001).

Although there is a robust literature supporting the empirical generalization that parental conflict is related to childhood problems, the research has primarily studied European American populations in the U.S. There is minimal research that investigates the relationship between marital distress and child outcomes in other cultures (Bradford et al., 2004; Buehler et al., 1997; Krishnakumar \& Buehler, 2000; Shek, 2001), including a specific lack of knowledge regarding Latino populations. This is a significant gap in the literature since Latino children make up the largest minority group in the U.S., accounting for $16 \%$ of children younger than 18 years of age (Flores, Fuentes-Afflick, Barbot, Carter-Pokras, Claudio, \& Lara, et al., 2002). The omission of Latinos is particularly relevant since there are currently over 37 million Latinos in the U.S., which comprises over $13 \%$ of the population (US Census Bureau, 2002). By the year 2030, Latinos are estimated to make up over $20 \%$ of the population (US Census Bureau, 2002). With this population growing rapidly in American society, it is important to

\footnotetext{
* 2086B JFSB, Brigham Young University, Provo, Utah 84602 USA.

${ }^{* *}$ Child, Youth and Family Studies, University of Nebraska-Lincoln, 130 Mabel Lee Hall, Lincoln, Nebraska 68588 USA.

*** Federal University of Rio Grande Do Sul, Rua Joao Abbott, $451 \mathrm{conj} 402,90460150$ Porto Alegre, RS, Brazil.
} 
better understand the dynamics of Latino families, including the relationship between marital conflict and offspring outcomes. The study is further justified given the relevance of the Brazilian population. Currently, Brazil is the fifth-largest country with respect to population and geography in the world. It is also the largest country, both geographically and populationwise in South America. Consequently, it is important to understand this country.

In addition, no research to date has examined the effect of marital relationships on child outcomes among younger children. The majority of studies investigating how parental conflict impacts child development is generalized to children six years of age and over (Depner et al., 1992). In addition, these ages coincide with expected detection of child adjustment problems. With the national median age for the emergence of socio-emotional and behavioral problems being approximately seven years (Zill \& Schoenborn, 1990), it would be helpful to study children who are younger. In the context of the existing literature, the purpose of this study was to assess the impact of the marital relationship on the outcome of four to five year old children in a Latino population.

Brazil is a unique sub-culture of Latinos. A differentiating factor is that Brazilians speak Portuguese instead of Spanish. In addition, there is a degree of diversity with respect to race due to immigration of both Europeans and Africans to Brazil and consequent integration through interracial marriages (Hollist, Falceto, \& Miller, in press). More prominent than the racial diversity is that Brazilians fall under the traditional Latino values of interdependence and hierarchical structure, given that the division of labor is specifically assigned into masculine and feminine tasks (Dessen \& Torres, 2002). In general, when present, the husband has power and authority over his family. Mothers tend to have very close relationships with children. Family conflict is often more present during transitions in adolescence, when old values regarding parental authority clash with ideals of greater independence for the youth (Dessens \& Torres, 2002).

\section{LITERATURE REVIEW}

The ecological-transactional theoretical model is a useful lens in understanding the relationship between marital quality and child development, especially in Latino families. This perspective suggests that children's experiences are being influenced by different levels of context (Belsky, 1981; Brofenbrenner, 1979; Cicchetti \& Lynch, 1993; Cicchetti \& Rizley, 1981; Lindahl, Malik, Kaczynski, \& Simons, 2004; Lynch \& Cicchetti, 1998). Individual development and functioning are affected by the microsystem, including family environment, communication, and relational patterns. In addition, there exist other influential systems, including the exosystem and the macrosystem. The exosystem refers to community and neighborhood influences, while the macrosystem refers to a variety of societal specific norms that act as messages, traditions, and practices for the formation of identity within specified populations.

This model addresses the impact of the environment outside of family interactions on children. These contextual elements are important to understand because they are part of a mutual transactional process that impacts child development (Lindahl et al., 2004; Lynch \& Cichetti, 1998). The microsystem addresses the most basic level of context, focusing on transactions 
between different subsystems, specifically, parent-child relationships. Interactions between these subsystems are related to consequent functioning (Lindahl et al., 2004). The microsystem is embedded in the exosystem, which accounts for more general messages received and exchanged with the neighborhood or community. These neighborhoods or communities are part of a greater whole, the macrosystem. Messages from the macrosystem might vary from one country or culture to another. For instance, there may be certain cultural norms in Brazil for parenting or family interactions that vary greatly from norms in the United States. For example, while the impact of marital discord on child outcomes is generally accepted with traditional European American population research, it is important to take into account possible cultural differences (Parke, 2004). With Latino families generally having more extensive extended family networks, some scholars have hypothesized that the effect of marital conflict on children would be moderated because of support from extended family members (Harrison, Wilson, Pine, Chan, \& Buriel, 1990; McLoyd, Harper, \& Copeland, 2001; Vega, 1990). Thus, the effect of marital conflict on children may be different in Latino families.

Research suggests that global marital satisfaction is not as strongly linked to child development outcomes as the concept of marital processes, such as conflict (Cummings \& Davies, 1994; Grych \& Fincham, 1990; Jouriles, Farris, \& McDonald, 1991; Katz \& Gottman, 1993). For instance, one longitudinal study that assessed marital satisfaction and marital interactions separately, found that marital satisfaction at time-1 was not predictive of child behavioral outcomes at time-2. However, hostility in particular was found to be predictive of child externalizing behaviors over time. These results, along with other empirical studies, support the hypothesis that specific types of marital conflict are more significant in predicting child outcomes than global marital satisfaction (Cummings \& Davies, 1994).

In general, there is a dearth of knowledge regarding the impact of marital conflict on children in other cultures. For example, there is still very little research documenting the impact of marital conflict on child outcomes in African American samples (e.g Krishnakumar et al., 2003). However, there are a few studies that have looked at the concept of family conflict, rather than marital conflict, and how it is associated with youth outcomes. For example, DuRant, Getts, Cadenhead, Emans, and Woods (1995) compared high conflict vs. low conflict African American couples. They found that youth with high conflict families were more likely to report child symptoms of depression, psychological distress, and less satisfaction with family environment and social lives. On a similar note, Mason, Cauce, \& Gonzales (1994) reported that increased family conflict was associated with more externalizing behaviors among children.

\section{Latino Studies}

A limited number of studies have examined the relationship between marital functioning and child outcomes among Latino families. Specifically, five studies to date have looked at the relationship between marital discord and child outcomes among Latino populations in the U.S. (Bradford et al., 2004; Gonzales, Pitts, Hill, \& Roosa, 2000; Lindahl \& Malik, 1999; Lindahl et al., 2004), while only one study has examined Latino families living in their native culture (Cummings, Wilson, \& Shamir, 2003). 
Gonzales et al., (2000) studied a non-random sample of 79 fourth-grade Mexican- American children from a lower SES population in Arizona. The researchers had the children report on parental behavior and conflict, and mothers reported on the children's behaviors using the Conduct Problem and Depression subscales of the Child Behavior Checklist (CBCL) (Achenbach \& Edelbrock, 1983). These researchers found that more frequent, intense, and unresolved parental conflict was associated with more symptoms of depression and conduct problems.

A retrospective study by Buehler \& Gerard (2002) looked at ethnicity and its relationship with interparental conflict and child outcomes. Although the overall percentage of the Latino population in the study was low in comparison with the primary European American population, the Latino sample size was large enough to yield interpretable results. They found a general association between marital conflict and negative child outcomes. The only exception was among children from ethnic, including Latino, backgrounds who were between the ages of 2 and 4 , where no significant relationship was found.

In the third study, Bradford et al., (2004) conducted a large U.S. national study of 9,050 adolescents from 11 different nationalities, including Colombia, to examine cross-cultural differences between youth in the sample. Adolescent self-reports were used to assess interparental conflict, parental support, and adolescent outcomes. Overall, they found that adolescents' reports of interparental conflict were associated with poor behavioral outcomes, regardless of the national-origin of the participants. When looking at the effect of different types of interparental conflict on Latino youth outcomes, the largest association found was between covert parental conflict that involves passive-aggressive behaviors and triangulating children and child depression. Overt conflict, such as yelling and arguing, had a less significant association with the child outcomes of depression and antisocial behavior.

Lindahl et al., (2004) did a comparison of European American and Latino American families, generally of Cuban descent. The sample consisted of 237 two-parent middle class families with children ranging from ages $8-12$. Out of the 237 families, $52 \%$ of fathers and $57 \%$ of mothers identified themselves as Latino. Assessment of the marital relationship was done using an observational method. Child adjustment was based on self-reports by parents using the CBCL (Achenbach \& Edelbrock, 1983). They found that child externalizing and internalizing behaviors were related to both verbally aggressive and coercive types of parental conflict for both European American and Latino families. However, they also reported that marital functioning was more predictive of child internalizing symptomalogy for European American couples, even after controlling for income.

Finally, a study by Lindahl \& Malik (1999) compared Hispanic American (primarily Cuban) and European American, and biracial families specifically with male child outcomes. They used self-report and observational instruments with 113 families who had children between the ages of 7 and 11 . Overall, results indicated that marital conflict was associated with child externalizing behaviors, regardless of ethnic group. However, the pathways in which marital conflict affected child outcomes differed by ethnicity. Lax and inconsistent parenting in Hispanic American families was associated with child externalizing behaviors, while hierarchical parenting styles were linked to externalizing behaviors among European American children. 
In addition, they found that higher family cohesiveness in Hispanic American families acted as a moderating variable between marital conflict and boys' externalizing behavior.

Only one study to date has looked at Latino families outside of the U.S. (Cummings et al., 2003). This study compared and contrasted 7-9 and 11-13 year old children from middle class families in the U.S. $(n=36)$ and in Chile $(n=36)$. The researchers found that marital discord was associated with child outcomes for both groups. Parents reported marital functioning by completing a marital discord scale (Porter \& O'Leary, 1980) and the Conflict Tactic Scale (Straus, 1979), along with the CBCL to measure child adjustment. Children responded to a series of questions based on recordings of positive and negative parental interaction vignettes. The children were asked to respond as if the adults they had listened to were their parents. Analyses of child responses based on children's reactions of anger and fear indicated that there were no significant differences between cultures with regards to reactions to marital discord. However, they found that Chilean children measured higher on sadness subscales when exposed to marital discord. Chileans also demonstrated more behavioral difficulties on internalizing and externalizing behavior scales when presented with marital discord. The researchers concluded that these findings were consistent with previous literature that explains conflict in Latino cultures as being discouraged and unacceptable.

The literature to date with Latino populations leaves us with some general ideas about how marital relations affect child outcomes. It appears that, overall, there are many similarities between cultures (Bradford et al., 2004; Lindahl \& Malik, 1999), with marital conflict affecting child outcomes in Latino, as well as European American families. However, all but one of the studies on Latino families was conducted among Latino families already living in the U.S., which exposes them to acculturation influences. The issue of acculturation relates back to the ecological-transactional theory. With respect to the different systems, microsystems would seem to be uniquely influenced by the greater contexts of the exosytem and macrosystem. For instance, immigrants in the United States are likely to be influenced by and conform in different degrees to the pre-dominant culture (Gonzales et al., 2000). These changes might manifest in different ways, such as changes in parenting style or desire for closeness in family relationships. Consequently, it is unclear whether the effects of marital conflict on child outcomes among these Latino families captures true Latino family process or whether it reflects the influence of American culture. The only study conducted with Latino children focused on 36 Chilean families (Cummings et al., 2003). Consequently, it is important to further study the effect of marital distress on children outcomes in native Latino families.

There are cultural aspects of Latino families living in their native culture that suggest that the effect of marital conflict on child outcomes may differ from those of European American families. Some have hypothesized that children from Latino families have extended family networks that moderate the relationship between marital distress and child outcomes (Harrison et al., 1990; McLoyd et al., 2001; Vega, 1990). In other words, Latino children living in home environments where marital conflict is present may have other available sources of social support apart from their parents, such as grandparents, godparents, aunts, uncles, and cousins.

In addition, there are some scholars that describe the Latino population as being more conflict avoidant in order to maintain stability and cohesion (Bornstein \& Cote, 2001; Buehler 
\& Gerard, 2002; Gabrieldis, Stephan, Ybarra, Person, \& Villareal, 1997; Garcia-Coll, Meyer, \& Brillon, 1995; Kagan, Knight, \& Martinez-Romero, 1982). Traditional Latino populations may place more emphasis on the unity and collective harmony than individual wants and needs. Indeed, the cultural norm of individualism (Triandis, Brislin, \& Hui, 1988) within the U.S. population may not be a norm that is shared with the Latino culture, where familism or collectivism is emphasized (Lindahl, et al., 2004). Consequently, rather than bringing up issues and introducing the possibility of conflict, the Latino culture may emphasize avoidance * in order to maintain the peace and unity of the family or group.

Previous research supports the idea that a disruption in the family's sense of collectivism can cause significantly more distress for Latino children compared to children of European American descent (Cummings et al., 2003; Garcia-Coll et al., 1995; Gonzales et al., 2000). Thus, it is possible that children in families characterized by marital or relational conflict are impacted more significantly than European American children due to the negative impact on group cohesion.

One conclusion that can be drawn from these theoretical perspectives is that Latino families are more likely to avoid conflict in order to maintain family stability. However, when marital conflict has become inevitable, it is unclear how Latino children might be impacted. It would seem plausible that Latino children would be more negatively impacted, compared to European Americans, by ruptures in family cohesion. At the same time, this instability might be moderated by the presence of extended family support, a primary characteristic of Latino families. Current research doesn't adequately address the complexity of these variables.

\section{Developmental Issues}

In addition to culture, another factor that seems to be less understood concerns the influence of children's age on the relationship between marital quality and child outcomes. Scholars have hypothesized that the toddler and preschool years are instrumental in child development (Easterbrooks \& Emde, 1988; Hockenberry, 2006), with much attention being given to the importance of attachment during this period (Rubin, Lemare, \& Lollis, 1990). Parent-child relations, which are often adversely effected in families where interparental conflict is present, has an important impact on the attachment of young children (Rubin et al., 1990). Consequently, it is important to examine the effect of marital conflict on young children.

However, nearly all of the studies that examine the effect of marital conflict on child outcomes have focused on comparison groups including children ages 7 and older. Research with Latinos is even less informative. One meta-analysis analyzed and compared different ethnic groups across various age groups and found that marital conflict was not associated with outcomes for non European American children, including Latinos, between the ages of 2 and 4 (Buehler \& Gerard, 2002). Another finding, related to the impact of age on Latino child outcomes is worth mentioning. Kagan et al., (1982) found that children's conflict responses positively correlate with age, in that, as Mexican children got older, they responded to marital conflict with increasingly more overt conflictive behaviors.

The current study, using data that were conducted in Southern Brazil, addressed these gaps in the research literature. The sample used in this study included nearly 100 families that had 
a child who was four years old. Consequently, this study expanded on the smaller study of native Chilean families (Cummings et al., 2003) by allowing the analysis of a larger sample of Latino families. Moreover, the inclusion of four year olds in the study allowed an explicit examination of the link between marital conflict and child outcomes among younger children. Thus, this study provided information on the importance of marital quality on the early development of children in Latino families.

Two sets of hypotheses were tested in this study. Consistent with research of European American families, our first hypothesis was that positive marital interactions would not be significant predictors of child outcomes among Brazilian families. In regards to the effect of marital conflict on child outcomes, the literature on marital conflict on children in Latino families suggests two competing hypotheses. First, there is a hypothesis that marital conflict is not associated with child behavioral outcomes. The underlying belief supporting this idea suggests that familial aspects of Latinos, such as the extended family, acts as a buffer for the effects of marital conflict (McLoyd et al., 2001). Second, there is empirical support (e.g., Cummings et al., 2003) for a contrasting hypothesis which suggests that there is an association between marital conflict and child outcomes. This reasoning is based on the importance of family cohesiveness or collectivism, when comprised by marital conflict, is believed to particularly impact Latino families (Lindahl et al., 2004).

\section{METHODS}

\section{Procedure}

The data for this study were part of a larger study of Brazilian family development that involved the collaboration of a university medical school in Southern Brazil, the hospital organization Grupo Hospitalar Conceição, and the Family Therapy Institute in Porto Alegre, Brazil. Porto Alegre, from where the sample was collected, uses a medical system where medical services are divided into geographic regions that are serviced by hospitals and clinics. Each region is divided into several districts, with each having its own health clinic that provides primary care services. The hospital group responsible for the region in which the study was conducted is called Grupo Hospitalar Conceição. The study was conducted in conjunction with three medical clinics, where about 18,000 people live.

In Brazil, the birth of children is registered by the local government and the information is sent to the medical region and district where the family lives (Hollist, Miller, \& Falceto, in press). All children born between March, 1999 and May, 2000 who lived in the areas covered by the three clinics were selected for the study. Researchers from the project were given contact information of the newborn children and their families and requested informed consent from them to participate in the study. Family interviews with those who consented were scheduled and performed by two family therapists and filmed by a medical student.

During the first wave of data collection, there were a total of 228 infant births reported. Due to medical and/or ethical reasons, 13 infants and their families were excluded from the study; 6 children were born to HIV-positive mothers, 2 children died prior to 4 months, 2 were excluded due to severe medical conditions, and 3 pairs of twins were among the excluded 
participants. Thus, overall, there were 215 families meeting inclusion criterion. Of the 215 families, 208 consented to participation. However, 62 families, due to time constraints, did not finish all of the initial questionnaires. Three attempts were made to include those families before they were dropped from the sample, yielding a $68 \%$ participation rate. Even though a number of possible participants dropped out, $97 \%$ of the respondents gave completed demographical data. In order to compare demographics of those who dropped out with those still involved in the study, $t$-tests were run, indicating no age, ethnic, nor income related differences between the two groups. Thus, there were no apparent effects of selection bias (Miller \& Wright, 1995).

Two years later, a second wave of data was collected from these families. There was an $18 \%$ loss from time-1 to time-2, as 125 participated in the second wave. Most of those who didn't remain for the second wave had relocated and couldn't be reached. In addition, because of budget constraints, data were not collected from the fathers. Additional t-tests, which were run to identify any possible attrition bias after the second wave of data collection, indicated no significant demographic differences.

After another two years, a third wave of data was collected when the children were an average of 4 years and 3 months old. Data were collected from mothers, children, and available fathers at the third wave. In wave three, all 125 participants responded and data was collected. No attempts were made to collect data from those who did not respond in wave-2.

\section{Sample Characteristics}

The data from wave three were used for these analyses. Wave three included a sample size of 125 mothers and 97 male partners. Of the 97 males, 85 were biological fathers and 12 were step-fathers. The subsample used in these analyses was 97 families because of the eligibility requirement that both parents had to respond to the wave- 3 questionnaire. The average age of mothers was 30.1 and average age for fathers/companions was 34.8. There were 56 girls and 41 boys, with the average age of 4.31 years. Mean family income for the sample was 885 Reals per month, which is the equivalent of about $\$ 320.00$ US dollars. The overall sample is diverse with respect to income, with mean values representative of a lower-middle class socioeconomic status. The sample was economically representative of this area of Brazil. Even though the population is regarded as Latino by virtue of country of residence, $60 \%$ were white, $24 \%$ were black, and $13 \%$ reported a mixed ethnical heritage. This ethnical breakdown is thought to be representative of this region in Brazil. The southern part of Brazil has a strong European ethnic influence, which accounts for the larger proportion of white participants than may be expected from northern areas of Brazil.

\section{Measurements}

\section{Child behavioral outcomes}

There are currently no instruments translated and validated to assess child development or outcomes in Brazil, so a psychometrically established measure could not be used in these analyses. Instead, child development was measured based on a factor analysis of behaviorally- 
related questions at Time- 3 as reported by each child's mother. Not enough partners responded to allow analyses of results based on partner reports. Four questions were used to measure behavioral development. The first question, translated into English, was "How is the child nowadays?" A three-point Likert scale ranging from (1) "well" to (3) "with significant problems" was used to respond to the question. A second item, with a three-point Likert scale ranging from (1) "easy" to (3) "difficult", was "He/she is a(an) ___ child? A third question was, "Have you noticed if your child is agitated?" "Yes" and "no" responses were given to this question. The question was reverse coded in order to fit the directionality of the other variables in the scale. The last question asked, "Does any of your child's behaviors make you or any other family members annoyed?" Responses ranged from (1) "never" to (3) "many times". The range for this scale was between 3 and 7, with higher scores indicative of more behavioral problems. Principle component analysis using the extraction method produced factor loadings of at least .683 , which is substantially higher than the minimally accepted level of .40 (Stevens, 1996). Analysis of the scale of the 4 items yielded a Cronbach alpha coefficient of .83 , indicating good reliability of the scale.

\section{Marital Conflict}

Three questions asked of both the mothers and their partners were used to measure marital conflict. The first question, translated into English, was "Do you often have arguments?" A three-point Likert scale had the following responses: (1) "yes" (2) "sometimes" and (3) "no". The other two questions were based on items from a translated version of the Revised Dyadic Adjustment Scale (RDAS) (Busby, Crane, \& Larson, 1995). (Because the Portuguese version of the RDAS had not been psychometrically validated, it was not used these analyses.) The second question was "How often do you and your partner quarrel?" A third question was, "How often do you and your mate get on each other's nerves?" For these two questions, the response options ranged from (0) "All the time" to (5) "Never". Principle component analysis using the extraction method produced a component matrix of .60 or greater for the three-item scale and a Cronbach's alpha coefficient of .77. These results suggest that the three items are adequate measures of the latent variable, marital conflict, for both husbands and,wives. Range of the latent variable spanned from 1 to 10 , with higher scores being indicative of less marital conflict.

\section{Positive Marital Interaction}

Four questions from the Portuguese translation of the RDAS were used to assess positive marital interactions. Questions that seemed to indicate examples of positive marital interactions were selected. They were: (1)"Do you and your mate engage in outside interests together?", (2)"How often do you work together on activities?", (3)"How often do you calmly discuss something?", (4)"How often do you have interesting conversations?" For these four questions, the response options ranged from (0) "Never" to (5) "Always". Analysis of the reduced RDAS scale resulted in a component matrix of at least .57 and a Cronbach's alpha coefficient of .68. Scores on the variable of positive marital interaction ranged from 0 to 20 , with higher scores associated with increased positive marital interactions. 


\section{Control Variables}

Consistent with the marital quality and child outcome literature (Parke, 2004), age, child gender, race, and income were included in the analysis as control variables. Age was measured by the respondents' reported years, and income was based on minimum salary, which is a common metric of income in Brazil. With regards to race, it should be emphasized that the goal of the study was to provide information with respect to the influence of marital relations on child outcomes in a Latino population. Although the sample is considered to be Latino due to the geographical location of the country, ethnicity was taken into consideration, given the racial diversity of Brazil. Hence, ethnicity was included as one of the control variables.

\section{RESULTS}

\section{Preliminary Analyses}

Before testing the main hypotheses of this study, descriptive statistics were conducted with key dependent and independent variables. The marital conflict scale, consisting of three questions for both women and partners had a mean of $8.2($ s.d.= 1.8) and $8.6($ s.d.= 1.4), respectively. Results from the positive marital interaction scale produced means of 11.6 (s.d.=3.5) for mothers and $11.9($ s.d.=3.2) for partners. Women and partners did not significantly very on either the marital conflict or positive marital interaction scales. The behavioral conflict scale, consisting of four questions, had a mean of 4.2.(s.d.=1.2).

\section{Multiple Regression Analyses}

\section{Marital Conflict.}

The scales constructed for child externalizing behaviors and marital conflict were used in regression analysis, along with the control variables, age, child gender, race, and income. Analyses were run on both partner's and mother's self-reports of conflict and were compared to mother reports of child externalizing behaviors. As shown in Table 1, results of the mothers' model indicated that the unstandardized regression coefficient for marital conflict was $.153(\mathrm{p}$ $<.05$ ). From this statistic one can infer that when controlling for mother's age, family income, and child's race and gender, each one unit increase in mother reports of marital conflict is associated with a 153 unit increase in child behavioral problems. None of the control variables were significant. Consequently, it is believed that factors such as mother's age, social status, and child's race and gender do not have a significant impact that is noteworthy. Results of the partner's model of marital conflict revealed a nonsignificant regression coefficient for marital conflict. ( $b=-.049, p=.63)$. Once again, none of the control variables were significant in the model.

\section{Positive marital interaction.}

When analyzing the association between the variables of positive marital interactions and child outcomes, analyses indicated that neither mother nor partner reports of positive marital 
interaction were significantly related to mother reports of child behavior outcomes. (See Table 2). In the mother's model, the unstandardized regression coefficient for positive marital interaction was $-.065(\mathrm{p}=.12)$, and none of the control variables were significant. The coefficient of positive marital interaction in the partners' model was -.059 $(\mathrm{p}=.2)$, and, again, none of the control variables were significant. Coefficients were: child gender $=-.117(p=.68)$, age $=-.004$ $(\mathrm{p}=.86)$, income $=0(\mathrm{p}=.1)$, race $=-.07(\mathrm{p}=.74)$. Once again, the control variables did not have a noteworthy impact. The only control variable that approached significance was that of income, at the .1 level.

Table 1.

\section{Marital Conflict Values}

(Unstandardized values with standard errors in parentheses; $\mathrm{N}=97$ )

\begin{tabular}{lll}
\hline & Mothers & Fathers \\
\hline Marital Conflict & $.153^{*}(.073)$ & $-.049(.100)$ \\
Income & $.000(.000)$ & $.000(.000)$ \\
Gender of Child & $-.005(.264)$ & $.165(.279)$ \\
Age of Parent & $.005(.021)$ & $.009(.029)$ \\
Ethnicity & $.039(.183)$ & $-.005(.023)$ \\
$\mathrm{R}^{\wedge}$ & $.092(1.12)$ & $.068(1.14)$ \\
\hline
\end{tabular}

${ }^{*} p<.05 .{ }^{* *} p<.01 .{ }^{* * *} p<.001$.

Table 2:

\section{Positive Marital Interaction Values}

(Unstandardized values with standard errors in parentheses; $N=97$ )

\begin{tabular}{lll}
\hline & Mothers & Fathers \\
\hline Positive Marital Interactions & $-.065(.041)$ & $-.059(.045)$ \\
Income & $.000(.000)$ & $.000(.000)$ \\
Gender of Child & $-.084(.284)$ & $-.117(.286)$ \\
Age of Parent & $-.015(.024)$ & $-.004(.022)$ \\
Ethnicity & $.035(.187)$ & $-.065(.194)$ \\
$\mathrm{R}^{\wedge} 2$ & $.07(1.16)$ & $.06(1.16)$ \\
\hline
\end{tabular}

${ }^{*} p<.05 .{ }^{* *} p<.01 .{ }^{* * *} p<.001$.

\section{DISCUSSION}

The results of this study support the first hypothesis. The results suggest that the presence of positive marital interactions between spouses was not associated with child behavioral outcomes. As previously mentioned, research suggests that global marital satisfaction is not as strongly linked to child development outcomes as the concept of marital processes, such as conflict (Cummings \& Davies, 1994; Grych \& Fincham, 1990; Jouriles, Farris, \& McDonald, 1991; Katz \& Gottman, 1993). Consequently, the current study used self report measures, based on mother and partner reports of positive marital interactions, to indicate a similar association with Latino populations. 
In regards to the effect of marital conflict on child outcomes, the literature on marital conflict on children in Latino families suggests two competing hypotheses. First, there is a hypothesis that marital conflict is not associated with child behavioral outcomes. The underlying belief supporting this idea suggests that familial aspects of Latinos, such as the extended family, acts as a buffer for the effects of marital conflict (McLoyd et al., 2001). Second, there is empirical support (e.g., Cummings et al., 2003) for a contrasting hypothesis which suggests that there is an association between marital conflict and child outcomes. With regards to the competing hypotheses, the evidence from the current study indicated that marital conflict and child outcomes were, indeed, related. This finding supports the importance of familism or collectivism in Latino families. While Latino families may be more likely to avoid conflict in order to maintain family stability, it is important to understand the effects of conflict. Consequently, when marital conflict has become inevitable, it seems that Latino children are impacted. Given the importance of family cohesion in the Latino culture, this would make intuitive sense. It would seem plausible that Latino children would be negatively impacted by ruptures in family cohesion. The other hypothesis, which suggested that other concepts of Latino families, such as extended families, did not act as a moderator for the impact of marital conflict on child behavioral outcomes.

This relationship was based on mother reports (not fathers) of marital conflict, which is consistent with other studies that have separated mothers' and fathers' perceptions of marital quality. Previous researchers have found that women are better "barometers" of the relationship than men are (Doss, Atkins, \& Christensen, 2003; Shill \& Lumly, 2002; Vangelista $\&$ Daly, 1997). This research also indicates that women, in general, are more likely to seek out treatment compared to men. Whether these findings are indicative of men being less aware of the relationship or less inclined to admit problems so as to avoid addressing them, requires further research (Moynehan \& Adams, 2007).

With respect to parent-child research, the most common parent participant in studies is usually the mother, with mothers being the sole reporter of information about marital conflict and child adjustment in nearly 50\% of studies (Depner et al., 1992). For example, the other study done in a native Latino country (Cummings et al., 2003) was based on reports of one parent, as opposed to both. When studies do report results based on different respondents, it is not uncommon to find differing results. One study reported that there was no association between fathers' reports of verbal aggression and child behavior problems, while a relationship between the two variables did exist based on mother reports (Lee, Beauregard, \& Bax, 2005). Similar results have been found with respect to differences between father and mother reports of both marital relations and parenting practices, and how they are differentially associated with child outcomes (e.g., Aunola \& Nurmi, 2005; Bishop, Spence, \& McDonald, 2003; Buehler et al., 1997)

In addition, given that this study included children 5 years and younger, it would make sense that mothers would be more aware of their child's difficulties and challenges. Other studies support the theory that mothers tend to respond and be more cognizant of their children's needs when compared to fathers, especially for younger children (e.g., Kochanska \& Aksan, 2004; Kotchanska, Aksan, Knaack, \& Rhines, 2004). 
Although there was a significant relationship between mothers' reports of marital conflict and child outcomes,.marital conflict accounted for only $9 \%$ of child outcome variance. Research, including meta-analyses and narrative reviews, with traditional European American populations has generally derived more significant results, with moderate effect sizes (Zimet \& Jacob, 2001). The results from this study demonstrate significant findings for a native Latino population, but they are not as strong as what previous research with European American populations has found.

A contribution of this study is its focus on younger children. Research with traditional populations has provided little understanding about earlier child development. The metaanalysis by Buehler \& Gerard (2002) showed a correlation between marital conflict and child outcomes for all age groups except for 2-4 year olds of non European American ethnic groups. The results from the current study provide evidence that marital conflict has an impact on early child development of Latino populations.

\section{Limitations \& Directions for Future Research}

Although the focus of this study is to report on potential similarities and differences across cultures, there are potential variations among different countries and cultures of Latin America. Thus, it is important that the results are not automatically generalized to other Latino cultures. While significant similarities are plausible, potential differences exist and should be further investigated in order to provide greater understanding of Latino populations. Research focused on other familial factors influencing child development has been critical in providing understanding regarding similarities and differences between cultures. For example, Olson, Yang, \& Hart (2002) have conducted research regarding parenting practices in the United States, Russia, and China and their impact on youth outcomes. Their findings, with other cross cultural research, has identified that certain types of parenting style constructs do not have an equal cross-cultural impact on youth. Consequently, these studies of child development should be used as a stepping stone towards more understanding of how familial factors, such as marital conflict, influence child development.

In addition, this study only focused on behavioral outcomes primarily indicative of externalizing child maladjustment. Future research should assess aspects of Latino offspring outcomes, characterized by internalizing difficulties such as depression and withdrawal.

These data are not longitudinal and, as such, present difficulties in assessing causality. Cross sectional studies don't account for the possibility that child behaviors may lead to marital conflict. Scholars have indicated the importance of using longitudinal studies in order to establish causality and model possible reciprocal relationships between parents and children (Buehler \& Gerard, 2002; Gonzales et al., 2000; Lindahl \& Malik, 1999). There are currently no longitudinal studies that examine the temporal ordering between child outcomes and marital conflict in Latino populations. Future research with Latino populations should implement data collection in at least three different time frames in order to more carefully examine causality between the variables.

This study does not address moderating variables between interparental conflict and child development outcomes. However, it would be important to investigate possible moderating 
and mediating variables such as resolution of conflict and spill-over effects into parenting within Latino families. For example, Davies \& Cummings (1994) have hypothesized that specific aspects of conflict such as frequency, type, resolution, and conflict may play a moderating role in child outcomes, related to marital conflict. The spill-over hypothesis is prominent in research with European American populations and is now being tested with other ethnic populations (e.g., Buehler, Benson, \& Gerard, 2006).

Furthermore, it would be important to assess the differential effect between overt and covert conflict and how these variables are associated with different types of child behaviors. Buehler, Krishnakumar, Gaye, Anthony, Pemberton, Gerard, \& Barber (1998) studied primarily European Americans and found that overt marital conflict was associated with child externalizing behaviors, while covert conflict was related to internalizing behaviors. In addition, future research should employ multiple observations of child behavior, not limited to mother reports alone. Perspectives from fathers, extended family, peers, and teachers would also be valuable in ascertaining a more detailed understanding of child behaviors in different domains.

In the trek for knowledge regarding the impact of marital relationships and their effect on child outcomes in Latino cultures, this study makes a meaningful contribution. Research linking the association between marital conflict and child maladjustment in European American populations can be extended into application with Latino cultures. This study also supports research done in the United States that finds marital conflict to be much more predictive than global marital satisfaction or positive marital interaction of child outcomes. However, a significant amount of research is still needed in order to replicate findings and further our understanding with regards to the Latino population. Future studies can increase our knowledge and provide information for clinicians who work with families and children from the fastest growing minority population in the United States.

\section{REFERENCES}

Achenbach, T. M., \& Edelbrock, C. S. (1983). Manual for the Child Behavior Checklist and Revised Child Behavior Profile. Burlington, VT: University of Vermont, Department of Psychiatry.

Aunola, K., \& Nurmi, J. (2005). The role of parenting styles in children's problem behavior. Child Development, 76, 1144-1159.

Belsky, J. (1981). Early human experience: A family perspective. Developmental Psychology, 17, 3-23.

Bishop, G., Spence, S.H., \& McDonald, C. (2003). Can parents and teachers provide a reliable and valid report of behavioral inhibition? Child Development, 74, 1899-1917. Block, J., Block, J., \& Gjerde, P. (1986). The personality of children prior to divorce: A prospective study. Child Development, 57, 827-840.

Bornstein, M.H., \& Cote, L.R. (2001). Mother-infant interaction and acculturation: I. Behavioural comparisons in Japanese American and South American families. International Journal of Behavioral Development, 25, 549-563.

Bradford, K., Barber, B.K., Olsen, J.A. Maughan, S.L., Erickson, L.D., Ward, D., \& Stolz, H.E. (2004). A multi-national study of interparental conflict, parenting, and adolescent functioning: South Africa, Bangladesh, China, India, Bosnia, Germany, Palestine, Colombia, and the United States. Marriage \& Family Review, 35, 107-137. 
Brofenbrenner, U. (1979). The ecology of human development: Experiments by nature and design. Cambridge, MA: Harvard University Press.

Buehler, C., \& Gerard, J.M. (2002). Marital conflict, ineffective parenting, and children's and adolescents' maladjustment. Journal of Marriage and Family, 64, 78-92.

Buehler, C., Krishnakumar, A., Gaye, S., Anthony, C., Pemberton, S., Gerard, J., \& Barber, B.K. (1997). Interparental conflict and youth problem behaviors: A meta-analysis. Journal of Child and Family Studies, 6, 223-247.

Buehler, C., Benson, M.J., \& Gerard, J.M. (2006). Interparental hostility and early adolescent problem behavior: The mediating role of specific aspects of parenting. Journal of Research on Adolescence, 16, 265-292.

Buehler, C., Krishnakumar, A., Gaye, S., Anthony, C., Pemberton, S., Gerard, J., \& Barber, B.K. (1998). Interparental conflict styles and youth problem behaviors: A two-sample replication study. Journal of Marriage and Family, 60, 119-132.

Busby, D.M., Crane, D.R., \& Larson, J.H. (1995). A revision of the dyadic adjustment scale for use with distressed and nondistressed couple: Construct hierarchy and multidimensional scales. Journal of Marital \& Family Therapy, 21, 289-308.

Cicchetti, D., \& Lynch, M. (1993). Toward an ecological/transactional model of community violence and child maltreatment: Consequences for children's development. Psychiatry: Interpersonal and Biological Processes, 56, 96-118.

Cicchetti, D., \& Rizley, R. (1981). Developmental perspectives on the etiology, intergenerational transmission, and sequelae of child maltreatment. New Directions for Child Development, 11, 31-56.

Cohen, J. (1988). Statistical power analyses for the social sciences. Hillsdale, NJ: Lawrence Erlbaum and Associates.

Cummings, E.M., \& Davies, P.T. (1994). Marital conflict and child adjustment: An emotional security hypothesis. Psychological Bulletin, 116, 387-411.

Cummings, E.M., Wilson, J., \& Shamir, H. (2003). Reactions of Chilean and US children to marital discord. International Journal of Behavioral Development, 27, 437-444.

Depner, C.E., Leino, E.V., \& Chun, A. (1992). Interparental conflict and child adjustment: A decade review and meta-analysis. Family \& Conciliation Courts Review, 30, 323-341.

Dessen, M.A., \& Torres, C.V. (2002). Family and socialization factors in Brazil: An overview. In W.J. Lonner, D.L. Dinnel, S.A. Hayes, \& D.N. Sattler (Eds.), Center for Cross-Cultural Research, Bellingham, WA.

Doss, B.D., Atkins, D.C., \& Christensen, A. (2003). Who's dragging their feet? Husband and wives seeking marital therapy. Journal of Marital \& Family Therapy, 29, 165-177.

DuRant, R., Getts, A., Cadenhead, C. (1995). Exposure to violence and victimization and depression, hopelessness, and purpose in life among adolescents living in and around public housing. Journal of Developmental \& Behavioral Pediatrics, 16, 233-237.

Easterbrooks, M.A., \& Emde, R.N. (1988). Marital and parent-child relationships: The role of affect in the family system. In R.A. Hinde \& J.S. Hinde (Eds.), Relationships within families: Mutual influences (pp.83-103). New York: Oxford University Press.

Erel, O., \& Burman, B. (1995). Interrelatedness of marital relations and parent-child relations: A metaanalytic review. Psychological Bulletin, 118, 108-132.

Fincham, F., \& Osborne, L. (1993). Marital conflict and children: Retrospect and prospect. Clinical Psychology Review, 13, 75-88. 
Flores, G., Fuentes-Afflick, E., Barbot, O., Carter-Pokras, O., Claudio, L., Lara, M. et al., (2002). The health of Latino children: Unanswered priorities, unanswered questions, and a research agenda. Journal of the American Medical Association, 288, 82-90.

Gabrieldis, C., Stephan, W.G., Ybarra, O., Person, V.M., \& Villareal, L. (1997). Preferred styles of conflict resolution in Mexico and the United States. Journal of Cross-Cultural Psychology, 28, 661677.

Garcia-Coll, C., Meyer, E.C., \& Brillon, L. (1995). Ethnic and minority parenting. In M.H. Bornstein (Ed.), Handbook of parenting: Vol. 2. Biology and ecology of parenting (pp. 189-209). Mahwah, NJ: Erlbaum.

Gonzales, N.A., Pitts, S.C., Hill, N.E., \& Roosa, M.W. (2000). A mediational model of the impact of interparental conflict on child adjustment on a multiethnic, low-income sample. Journal of Family Psychology, 14, 365-379.

Grych, J., \& Fincham, F. (1990). Marital conflict and children's adjustment: A cognitive-contextual framework. Psychological Bulletin, 108, 267-290.

Grych, J., \& Fincham, F. (Eds.). (2001). Interparental conflict and child development: Theory, research, and applications. Cambridge: Cambridge University Press.

Harrison, A.O., Wilson, M.N., Pine, C.J., Chan, S.Q., \& Buriel, R. (1990). Family ecologies of ethnic minority children. Child Development, 60, 1044-1051.

Hockenberry, L. (2006). What kids need: Today's best ideas for nurturing, teaching, and protecting young children. Family Relations: Interdisciplinary Journal of Applied Family Studies, 55, 150.

Hollist, C.S., Miller, R.B., Falceto, O.G. (In progress). Marital satisfaction and depression: A crosscultural test of the marital discord model of depression.

Jouriles, E., Farris, A., \& McDonald, R. (1991). Marital functioning and child behavior: Measuring specific aspects of the marital relationship. In (Ed.), Advances in family intervention, assessment and theory (pp.25-46). London: Jessica Kingsly.

Kagan, S., Knight, G.P., \& Martinez-Romero, S. (1982). Culture and the development of conflict resolution style. Journal of Cross-Cultural Psychology, 13, 43-58.

Katz, L.F., \& Gottman, J. M. (1993). Patterns of marital conflict predict children's internalizing and externalizing behaviors. Developmental Psychology, 29, 940-950.

Kolko, J.R., Blakely, E.H., \& Engleman, D. (1996). Children who witness domestic violence: A review of empirical literature. Journal of Interpersonal Violence, 11, 281-293.

Kochanska, G, \& Aksan, N. (2004). Development of mutual responsiveness between parents and their young children. Child Development, 75, 1657-1676.

Kochanska, G. Aksan, N., Knaack, A., \& Rhines, H.M. (2004). Maternal parenting and children's conscience: Early security as moderator. Child Development, 75, 1229-1242.

Krishnakumar, A., \& Buehler, C. (2000). Interparental conflict and parenting behaviors: A metaanalytic review. Family Relations, 49, 25-44.

Krishnakumar, A., Buehler, C., \& Barber, B.K. (2003). Youth perceptions of interparental conflict, ineffective parenting, and youth problem behaviors in European American and African-American families. Journal of Social and Personal Relationships, 20, 239-260.

Lee, C.M., Beauregard, C., \& Bax, K.A. (2005). Child-related disagreements, verbal aggression, and children's internalizing and externalizing behavior problems. Journal of Family Psychology, 19, 237345 . 
Lindahl, K., \& Malik, N. (1999). Marital conflict, family process, and boys' externalizing behavior in Hispanic American and European American families. Journal of Clinical Child Psychology, 28, 12-24.

Lindahl, K.M., Malik, N.M., Kaczynski, K., \& Simons, S. (2004). Couple power dynamics, systemic family functioning, and child adjustment: A test of a mediational model in a multiethnic sample. Development and Psychopathology, 16, 609-630.

Lynch, M., \& Cicchetti, D. (1998). An ecological-transactional analysis of children and contexts: The longitudinal interplay among child maltreatment, community violence, and children's symptomatology. Development and Psychopathology, 10, 235-257.

Mason, C., Cauce, A., \& Gonzales, N. (1994). An ecological model of externalizing behaviors in African-American adolescents: No family is an island. Journal of Adolescence, 4, 639-655.

McLoyd, V.C., Harper, C.I., \& Copeland, N.L. (2001). Ethnic minority status, interparental conflict, and child adjustment. In J.H. Grych \& F.D. Fincham (Eds.), Interparental conflict and child development: Theory, research, and applications (pp.98-125). New York: Free Press.

Miller, R. B. \& Wright, D. W. (1995) Detecting and correcting attrition bias in longitudinal family research. Journal of Marriage and the Family, 57, 921-929.

Moynehan, J., \& Adams, J. (2007). What's the problem? A look at men in marital therapy. American Journal of Family Therapy, 35, 41-51.

Olsen, S., Yang, C., \& Hart, C. (2002). Maternal psychological control and preschool children's behavioral outcomes in China, Russia, and the United States. In X. Chen, D.C.

French, \& B.H. Schneider (Eds.) Intrusive parenting: How psychological control affects children and adolescents (pp.235-262). Washington D.C.: American Psychological Association.

Parke, R. (2004). Development in the family. Annual Review of Psychology, 55, 365-399.

Porter, B., \& O'Leary, K.D. (1980). Marital discord and childhood behaviour problems. Journal of . Abnormal Child Psychology, 8, 287-295.

Reid, W., \& Crisafulli, A. (1990). Marital discord and child behavior problems: A meta-analysis. Journal of Abnormal Child Psychology, 18, 105-117.

Rubin, K.H., LeMare, L.J., Lollis, S. (1990). Social withdrawal in childhood: Developmental pathways to peer rejection. In J.D. Coie \& S.R. Asher (Eds.), Peer rejection in childhood (pp.217-249). New York: Cambridge University Press.

Shek, D.T.L. (2001). Patemal and maternal influences on family functioning among Hong Kong Chinese families. The Journal of Genetic Psychology, 162, 56-74.

Shill, M.A., \& Lunley, M.A. (2002). The psychological-mindedness scale: Factor structure, convergent validity and gender in a non-psychiatric sample. Psychology and Psychotherapy: Theory, Research and Practice, 75, 131-150.

Straus, M.A. (1979). Measuring intrafamily conflict and violence. The Conflict Tactics (CT) Scales. Journal of Marriage and the Family, 41, 75-88.

Triandis, H.C., Brislin, R.W., \& Hui, C.H. (1988). Cross-cultural training across the individualismcollectivism divide. International Journal of Intercultural Relations, 12, 269-289.

US Census Bureau, (2002). Census 2000 Briefs and Special Reports (Published online at http:// www.census.gov/population/www/cen2000/briefs.html). Washington, DC: Author.

Vangelista, A.L., \& Daly, J.A. (1997). Gender differences in standards for romantic relationships. Personal Relationships, 4, 203-219. 
Vega, W.A. (1990). Hispanic families in the 1980's: A decade of research. Journal of Marriage and the Family, 52, 1015-1024.

Zill, N., \& Schoenborn, C.A. (1990). Developmental, learning, and emotional problems: Health of our nation's children, United States, 1988. Advance data from vital and health statistics of the national center for health statistics, 190, 1-18

Zimet, D.M., \& Jacob, T. (2001). Influences of marital conflict on child adjustment: Review of theory and research. Clinical Child and Family Psychology Review, 4, 319-335. 